\title{
Constituindo coletivos de humanos e não humanos: a ordenação do mundo
}

\section{Constituting human and non-human \\ collectivities: ordering the world}

\author{
Rafael Bennertz \\ Doutorando em Política Científica e Tecnológica/Universidade Estadual de Campinas. \\ rafael.bennertz@gmail.com
}

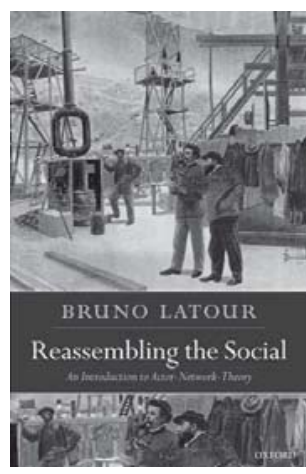

LATOUR, Bruno. an introduction to

Actor-Network-Theory.

Oxford: Oxford

University Press, 2005.

$301 \mathrm{p}$. (Claredon

Lectures in

Management Studies).
Reassembling the social:

A teoria ator-rede (TAR) desenvolveu-se a partir de um conjunto de estudos sobre a dinâmica de produção de conhecimento em laboratórios e de artefatos tecnológicos, realizada principalmente por Bruno Latour, Michel Callon e John Law. Esses trabalhos compreendem tanto estudos empíricos (Law, Callon, 1988, 1992; Callon, 1987; Latour, 1996, 1988; Latour, Woolgar, 1997; Law, 1987, 2002) quanto reflexões teóricas (Callon, Law, 1997; Law, Hassard, 1999; Law, Urry, 2004; Latour, 1988. Nesse sentido, Reassembling the social, de Bruno Latour, é ao mesmo tempo obra introdutória e guia de trabalho tanto para aqueles que se estão inserindo nos estudos sociais da ciência e tecnologia a partir da perspectiva da TAR, quanto para os já 'iniciados'. A proposição central de Latour é o abandono da sociologia como ciência da sociedade e a adoção de uma 'ciência das associações'. Argumenta o autor que a tarefa da sociologia é traçar as 'associações', 'reassociações' e 'reconfigurações' entre 'agentes humanos e não humanos', que compõem o mundo.

Para detalhar essa proposta, o livro é organizado em três partes, que delineiam as tarefas atribuídas ao sociólogo das associações para compreender a constituição do mundo. Primeiro, é preciso identificar e organizar (to deploy) as inúmeras controvérsias sobre as associações, sem distinguir a priori o social e o técnico. Segundo, traçar as associações que permitem aos atores estabilizar tais controvérsias. E, por último, é necessário reconfigurar o social em um coletivo reescrevendo a narrativa da constituição do mundo, evitando os tradicionais substantivos 'sociedade' e 'natureza'.

Nos cinco capítulos que compõem a primeira parte do livro Latour argumenta que, ao seguir o fechamento das controvérsias sobre a natureza dos grupos, da ação, dos objetos, dos fatos científicos e da base empírica das ciências sociais, o sociólogo das associações é capaz de compreender como são estabelecidas associações - frágeis, incertas, controversas e maleáveis - entre os elementos heterogêneos que constituem o mundo. O resultado da associação desses elementos heterogêneos deixa de ser a sociedade como entidade estática 
e objetiva, que passa a ser compreendida como coletividades compostas por associações de agentes cuja natureza e identidades são diversas. A distinção desses agentes só é definida após a estabilização, mesmo que momentânea, das controvérsias sobre a ontologia dos objetos.

Para compreender a natureza dos agentes que compõem o social, é fundamental observar a diferença entre intermediários e mediadores. Os primeiros são as entidades que transportam significados e informações sem as transformar; os mediadores, por sua vez, são as entidades que transportam significados, transformam, traduzem, distorcem, modificando-os e fazendo outras entidades agirem (p.39). Por terem a capacidade de gerar ações pela transformação de significados, forças e informações, os mediadores são apreendidos como atores, humanos ou não humanos, porque atuam ou fazem outras entidades atuarem na constituição do mundo.

Não existem grupos estáticos, mas sim processos contínuos de formação dos grupos. A constituição dos grupos é, nesse sentido, a constante redefinição da identidade do grupo, dos seus objetivos, das suas limitações e das suas características, realizada pelos porta-vozes do grupo na oposição a outros grupos, na ação dos próprios membros dos grupos e pelos cientistas sociais. A ação, por sua vez, não é apenas aquilo que o autor realiza conscientemente. A natureza, a forma e o modo de agir dos mediadores devem ser estudados seguindo-se as associações estabelecidas pelos próprios atores entre entidades heterogêneas. Dessa forma, ao ampliarem as fontes de agências, os atores demonstram que atuam sob a influência de um ou de diversos mediadores, que podem ser objetos.

Por muito tempo as ciências sociais negaram papel ativo aos objetos, mas eles são elementos constituintes do social. É na perspectiva de que os objetos podem ter agência fazem as demais entidades agirem - que os atores não humanos, os objetos, podem ser agentes da ação. Os objetos estabilizam as associações e conferem durabilidade à sociedade, fazendo com que as associações entre elementos heterogêneos se propaguem no tempo e no espaço.

Assim como um objeto, um fato científico é dotado de uma multiplicidade ontológica, resultante da sua constituição. Assim, os fatos científicos são mediadores, pontos de interconexão de diversas entidades, e a atuação deles translada, transporta, modifica informações e se associa a outros elementos dessas redes. Portanto, os fatos científicos não são ontologicamente distintos dos objetos; são elementos cuja gênese deve ser explicada e não explicativa.

Para compreender a gênese dos fatos científicos o sociólogo das associações precisa observar a prática científica enquanto os fatos científicos ainda não se estabilizaram e as diversas controvérsias sobre os fatos e sua interpretação ainda não se fecharam. Cabe compreender como as controvérsias sobre questões factuais e conceituais são encerradas na construção dos fatos e como suas identidades são estabilizadas.

Para o cientista social, o texto é seu laboratório, o local onde são criados os fatos científicos, onde são feitas as translações, onde diversos atores e associações são descritos, ou seja, onde objetos e conceitos são ordenados. Portanto, a base empírica das ciências sociais é evidenciada por uma descrição detalhada e objetiva dos rastros que os atores deixaram, que é alcançada com a manutenção de registros de pesquisa como anotações do 
pesquisador: "Se você não quer tomar notas e escrever, bem, não tente entrar para a sociologia: é a única maneira de se tornar um pouco mais objetivo" (p.135). Produzir dados empíricos precisos requer a manutenção dos traços estabelecidos pela própria pesquisa, de modo a proporcionar uma visão detalhada sobre como o mundo vai sendo construído pelo sociólogo das associações.

$\mathrm{Na}$ segunda parte de Reassembling the social, abordam-se as formas pelas quais as controvérsias são encerradas e mantidas estáveis. Para compreender como as controvérsias são fechadas pelos atores, Latour sugere a realização de três movimentos distintos: (1) a relocalização do global; (2) a redistribuição do local; e (3) a conexão entre global e local, revelados pelos movimentos anteriores, dando ênfase aos meios que possibilitam compreender o social como fluxos de associações.

Para realizar a relocalização do global evitando a distinção entre micro e macro, é importante identificar onde e como são produzidos as informações e os mecanismos que associam o local ao global. O tamanho de um ator ou um mediador depende diretamente da quantidade de associações estabelecidas e mantidas: pequeno é aquele com poucas conexões e grande, o que foi capaz de manter várias entidades conectadas.

Para Latour, os sociólogos do social devem basear a sua descrição nas formas que os próprios atores estabelecem para definir escalas sobre si ou outros atores/mediadores, e para definir os espaços, contextualizando sua realidade por meio da translação de informações e forças. Para isso, os próprios atores evidenciam como, em determinado momento, se inserem num contexto micro (com poucas associações) e no momento seguinte se associam a atores mais complexos, espalhados por todo o coletivo. Essa mobilidade é visualizada na descrição dos atores sobre o contexto em que se inserem, principalmente em editoriais de jornais, livros, discursos políticos, manifestações científicas, ou seja, quando os atores descrevem o 'todo' em que estão inseridos. São, portanto, informações importantíssimas sobre como os próprios atores visualizam o coletivo a partir dos seus locais de ação.

Da mesma maneira que o global é constituído pela justaposição de diversas cadeias de associações locais, o local é composto por associações estabilizadas e materializadas em objetos, que podem ser transportadas no tempo e no espaço para outras associações e podem tornar-se parte constitutiva de outros locais. As agências associadas continuam agindo por meio dos objetos que permanecem articulando e localizando os espaços locais - a multidão se esconde atrás das materializações! Por sua característica justaposta, o local é redistribuído considerando-se que entidades heterogêneas, tanto de natureza distintas como de gênese temporal e espacialmente diversas, agem nos locais.

O que distingue o local do global não é o aspecto geográfico, pois ambos são entidades/ espaços compostos em formato de redes, a unir entidades heterogêneas, mas sim aquilo que é transportado, a quantidade de associações e a maneira pela qual elas ensejam a ação de outros atores. Quanto maior for o número de associações, mais livre será o ator, justamente porque terá mais opções de ação (p.216).

Se tanto o global quanto o local são ressituados no tempo e no espaço e não configuram duas dimensões analiticamente distintas, o terceiro movimento apresenta as formas pelas quais ambos se interligam e como são construídas as diferenças de tamanho entre eles. Os tipos de conectores entre o global e o local que transportam agência de forma eficiente 
podem ser encontrados nas entidades, nos movimentos, nas forças, nos objetos, nas associações que estabilizam as controvérsias. Padrões e metrologia são ferramentas essenciais na estabilização de controvérsias e no transporte de agências; ambos oferecem um vocabulário que possibilita ao local se relacionar com o global. Ao utilizar-se de padrões e da metrologia, é possível realizar comparações tornando o mundo mensurável em unidades de medida, unidades monetárias e outros padrões de classificação compartilhados. Embora sejam convenções, os padrões e a metrologia são altamente práticos e possibilitam a associação entre entidades, por sua vez associadas a atores-redes locais e a atores-redes globais.

As teorias científicas atuam de maneira semelhante a essas convenções. Elas têm importância especial no que concerne à oferta de novas maneiras de compreender o mundo, enfatizando a ação de diferentes agências. Ao mesmo tempo, as teorias científicas oferecem explicações sobre como o mundo é e propõem configurações sobre como ele deveria ser afirmações sobre como as associações foram estabelecidas e como devem ser (re)conectadas. Para Latour, "o social que constrói a sociedade é apenas uma parte das associações que constroem o coletivo. Se quisermos reassociar o social, é necessário distanciar-se da circulação e da formatação de laços sociais tradicionalmente concebidos e detectar outras entidades circulantes" (p.233). Deve-se dar importância às agências nos objetos, às maneiras pelas quais estes fazem outros atores agirem, especialmente quando possibilitam associações. A natureza das agências, nos objetos, é de conexão, porque reconfigura a noção de mediador, de forma que este passa a ser o centro do estudo. Os mediadores são as associações encontradas nas tramas do fluxo social em formas estabilizadas e padronizadas, podendo ser transportados no tempo e no espaço, a exemplo de documentos legais, padrões métricos, fluxogramas, computadores ou até mesmo as diversas formas de embarcações marítimas que se associaram a elementos distintos e atuaram de modo diverso na expansão marítima portuguesa (Law, 1987) - e os aviões militares - que deixaram de representar os interesses britânicos do pós-guerra (Law, 2002; Law, Callon, 1988, 1992).

Mas e os fluxos de associações que não estão estabilizados? E os elementos que não estão padronizados ou que não estão sendo visivelmente transportados do local para o global e vice-versa? Seria o caso da inexistência de outras entidades, durante os processos de associação? Fica de fora dessas conexões uma quantidade imensurável de entidades que compõem o micro, apresentando apenas uma face da sua existência para construir um todo provisório. As entidades fora das associações são inúmeras e têm potencialidades e fluxos muito diversos. Elas ainda não foram sistematizadas, envolvidas em cadeias metrológicas, pesquisadas, mobilizadas e subjetivadas. Sua existência demonstra, justamente, que nossa ignorância sobre as trocas que compõem o social é imensa, porque não sabemos nada a respeito do que Latour denomina plasma (p.244). O plasma não é uma força invisível que atua de forma obscura; é apenas o conjunto de entidades desconhecidas, presentes no fluxo de transações no meio social e ainda não mapeadas pelos sociólogos das associações.

Reescrever a narrativa de constituição do social e reconfigurar o social em um coletivo implicam tornar o social estabilizado. É na forma como as diversas entidades que povoam o mundo são contabilizadas, avaliadas e padronizadas que reside a relevância política da sociologia das associações. Da mesma forma como são criadas metrologias e padrões capazes 
de sistematizar a forma como as entidades se associam, as ciências sociais em geral - e a sociologia especificamente - cogitam como é o mundo e como ele deveria ser. A relevância política dessa forma de compreender o mundo demonstra a importância de levar em conta a diversidade de entidades a agir no mundo, ao mesmo tempo que fornece um repertório capaz de propor a criação de associações entre novas entidades. Possibilita propor associações melhores do que as disponíveis até o momento.

Criar uma nova descrição do mundo é, ao mesmo tempo, proporcionar novas formas de associações e ação no mundo. É, portanto, impossível separar o rigor acadêmico da relevância política, porque nessa abordagem a ciência tem um papel político intrínseco. Ao propor o alistamento, a reabertura das controvérsias sobre a composição do mundo e a observação de como elas são estabilizadas, a TAR "procura meios de registrar a novidade das associações e explorar como realizar essas associações de forma satisfatória" (p.261), e atribui à sociologia a tarefa política de encontrar a melhor maneira para vivermos em um mundo aceitável para todos aqueles que serão associados. Será possível vivermos juntos? Latour pensa que sim, e seu projeto político é, ao mesmo tempo, proporcionar descrições das novas associações e oferecer opções de novas associações, melhores do que as anteriores.

Por fim, é importante observar que o livro busca dialogar com teóricos de diversas disciplinas, o que o torna teoricamente denso mas repleto de argumentos bem estruturados, que proporcionam uma compreensão da dinâmica das relações entre ciência, tecnologia e sociedade que transcende os determinismos social e tecnológico. Apesar de propor uma sociologia das associações em detrimento da sociologia 'do social', o livro parece ter mais aceitação entre aqueles dedicados aos estudos sociais de ciência e tecnologia do que entre os que se interessam pela teoria social. Para estes últimos, fica a indicação!

\section{REFERÊNCIAS}

CALLON, Michel.

Society in the making: the study of technology as a tool for sociological analysis. In: Bijker, Wiebe; Hughes, Thomas P.; Pinch, Trevor (Org). The social construction of technological systems: new directions in the sociology and history of technology. Baskerville: MIT Press. p.83-103. 1987.

CALLON, Michel; LAW, John.

After the individual in society: lessons in collectivity from science, technology and society. Canadian Journal of Sociology, Edmonton, v.22, n.2, p.165-182. 1997.

LATOUR, Bruno.

Aramis or The love of technology. Transl., Catherine Porter. Cambridge: Harvard University Press. 1996.

LATOUR, Bruno.

The pasteurization of France. Cambridge: Harvard University Press. 1988.
LATOUR, Bruno; WOOLGAR, Steve.

A vida de laboratório: a produção de fatos científicos. Rio de Janeiro: Relume Dumará. 1997.

LAW, John.

Aircraft stories: decentering the object in technoscience. Durham: Duke University Press. 2002.

LAW, John.

Technology, closure and heterogeneous engineering: the case of the Portuguese expansion. In: Bijker, Wiebe; Hughes, Thomas P.; Pinch, Trevor (Org). The social construction of technological systems: new directions in the sociology and history of technology. Baskerville: MIT Press. p.111-134. 1987.

LAW, John; CALLON, Michel.

The life and death of an aircraft: a network analysis of technical change. In: Bijker, Wiebe E.; Law, John (Org.). Shaping technology / 
Rafael Bennertz

Building society: studies in sociotechnical change. Cambridge: MIT Press. p.21-52. 1992.

LAW, John; CALLON, Michel.

Engineering and sociology in a military aircraft project: a network analysis of technical change. Social Problems, Berkeley, v.35, n.3, p.284-97. 1988.
LAW, John; HASSARD, John (Org.). Actor network theory and after. Oxford: Blackwell. 1999.

LAW, John; URRY, John.

Enacting the social. Economy and Society, London, v.33, n.3. p.290-310. 2004. 